\section{Incidence rates of chronic lymphocytic leukemia in US states are associated with residential radon levels}

\author{
Gary G Schwartz ${ }^{* 1}$ \& Marilyn G Klug²
}

\begin{abstract}
Aim: Environmental risk factors for chronic lymphocytic leukemia (CLL) have not been consistently identified. An etiologic role for ionizing radiation in CLL is controversial. Because most of the ionizing radiation to which individuals are exposed comes from radon at home, we examined CLL incidence rates in relation to residential radon levels. Methods: We used population-based rates for CLL for US states from 2007 to 2011 and measurements of residential radon made by the US Environmental Protection Agency. Results: Incidence rates for CLL were significantly correlated with residential radon levels among whites (both genders together and each gender separately; $p<0.005)$ and among blacks $(p<0.05)$. Conclusion: We speculate that radon increases CLL risk and that the mechanisms may be similar to those by which radon causes lung cancer.
\end{abstract}

First draft submitted: 23 September 2015; Accepted for publication: 7 October 2015; Published online: 30 October 2015

Chronic lymphocytic leukemia/small lymphocytic lymphoma (henceforth CLL) is a monoclonal disorder characterized by the accumulation of functionally incompetent, mature B lymphocytes [1]. It is the most common leukemia of adults in western countries and accounts for $30 \%$ of all leukemias. Conversely, CLL is rare in Asia where it comprises less than 5\% of leukemias [2]. There are approximately 15,000 new cases and 5000 CLL-related deaths per year in the US. CLL typically is a disease of the elderly and develops from a benign proliferation of monoclonal $\mathrm{B}$ cells (monoclonal B-cell lymphocytosis; MBL) that occurs in approximately $5 \%$ of normal individuals. MBL progresses to CLL at a rate of about $1-2 \%$ per year [3].

The best established risk factor for CLL is a family history of hematologic malignancy [4]. In contrast, environmental risk factors for CLL have not been reliably identified [5]. There is inconsistent evidence for an etiologic role of exposure to farming, pesticides and a protective role of exposure to sunlight [6,7]. Although ionizing radiation is known to cause other types of leukemia, CLL has not been associated with ionizing radiation in several highly exposed populations and thus CLL is generally considered to be nonradiogenic [8]. However, reports of increased risks of CLL among uranium miners and among some workers at nuclear power plants have challenged that view [9-12].

The majority of the exposure of most individuals to ionizing radiation comes from exposure to radon at home. Radon (radon-222) is a natural radioactive gas that is a product of the decay of the radioactive elements radium, thorium and uranium that are widely distributed in rocks and soils. Radon is the second largest cause of deaths from lung cancer, accounting for 10-15\% of deaths from

'Department of Population Health, University of North Dakota School of Medicine \& Health Sciences, Grand Forks, ND 58202, USA ${ }^{2}$ Department of Family Medicine \& Center for Rural Health, University of North Dakota School of Medicine \& Health Sciences, Grand Forks, ND 58202, USA

*Author for correspondence: Tel.: +1 701777 6598; Fax: +1 701777 0980; gary.schwartz@med.und.edu

\section{KEYWORDS}

- chronic lymphocytic leukemia • epidemiology - geography • incidence - ionizing radiation • radon 
lung cancer in the USA per year [13,14]. Radon gas enters homes via a gradient of negative pressure that pulls soil gases into the lowest level of the dwelling. Consequently, average radon levels indoors in the USA are significantly higher than average levels outdoors (1.4 vs 0.4 picoCuries/1 [piC/l]; 52 vs 15 Becquerels [Bq/m³]) [15].

As part of the National Residential Radon Survey, the US Environmental Protection Agency (EPA) placed long-term radon monitors in a stratified sample of 5694 homes across the USA. The data from that study were used to create the EPA map of radon zones (MRZ) $[15,16]$. We analyzed data from the MRZ in relation to age-adjusted incidence rates for CLL in US states. We report that the incidence of CLL in whites and blacks is positively correlated with measurements of residential radon.

\section{Methods}

Age-adjusted incidence rates of CLL for US states and the District of Columbia were obtained from a population-based registry, the National Association of Central Cancer Registries (NAACCR) [17]. Rates were age-adjusted to the USA 2000 population. Age-adjustment assures that the differences in rates are not confounded by differences in the age-distributions of the populations in different states. Data were obtained for males, females, non-Hispanic whites and non-Hispanic blacks. Because CLL incidence rates are significantly lower among Hispanic than among non-Hispanic whites, we used data on non-Hispanic whites and non-Hispanic blacks [18]. Rates with fewer than ten cases were considered unstable and were censored.

The classification of CLL was revised in 2008. Before 2008, CLL was classified using the 1996 guidelines of the National Cancer Institute Working Group (NCI-WG 96) which required an absolute lymphocyte count $>5 \times 10^{9}$ cells $/$. In 2008, the International Workshop of CLL (IWCLL 2008) updated these guidelines to require a lymphocyte count of B cells $>5 \times 10^{9}$ cells $/$ l. Because differences in the classification of CLL could influence the relationship between CLL and radon, we examined the relationship of CLL incidence rates and radon levels separately for 2007-2011 (which include the effects of the NCI-WG 96 and IWCLL 2008 guidelines) and for 2009-2011 (which should reflect the IWCLL guidelines only).

The MRZ was based on measurements obtained from radon detectors that were placed in homes selected to be representative of the US housing stock. In order to minimize statistical and weather-related variation, the detectors were kept in place for 1 year and were monitored to verify correct placement in the homes [16]. The MRZ assigned USA counties to one of three zones. Counties with the lowest potential for radon have a mean indoor radon level $<2 \mathrm{pCi} / \mathrm{l}$; those with moderate potential have a level $2-4 \mathrm{pCi} / 1$, and those with the highest potential have radon levels $>4 \mathrm{pCi} / \mathrm{l}$. We calculated a weighted measure of radon for each state, as follows. The number of counties with low, moderate and highest radon potential within each state was determined from the MRZ. We multiplied the number of counties in each category by a weight for the radon potential of that county. We gave counties with low radon potential a weight of 1.5 and counties with moderate potential a weight of three. Because $5 \%$ of USA homes have radon levels between 4 and $8 \mathrm{pCi} / \mathrm{l}$, we used the midpoint of that range (six) for the weight of the highest radon category. The weighted radon value for each state was the sum of the product of the number of counties with low, moderate and high radon potential and their corresponding weights, divided by the number of counties. We explored the effects of other weighting schemes to determine whether the results depended on the weighting. We estimated the direction and strength the relationships between statewide incidence rates for CLL and radon levels by linear regression. Differences in the linear relationships over different time periods were tested by analysis of covariance (ANCOVA). Analyses were performed using SAS (v 9.4; SAS Institute Inc., Cary, NC, USA).

\section{Results}

Data on CLL were not available for Arkansas, Minnesota and Nevada. During 2007-2011, 15 registries reported fewer than ten black cases, leaving data for blacks for 33 states. The data for blacks were too unstable for meaningful analyses stratified by gender. A total of 197 counties of the 3141 counties $(6 \%)$ did not report radon levels and were censored.

Incidence rates for CLL in 2007-2011 in whites ranged nearly 2.5-fold and were highest in North Dakota, 7.33 per 100,000, and lowest in Washington, DC, and Arizona, 3.01 per 100,000 (see Figure 1). Weighted radon levels ranged fourfold and were highest in North Dakota and Iowa and were lowest in Hawaii, Louisiana and Washington DC. 


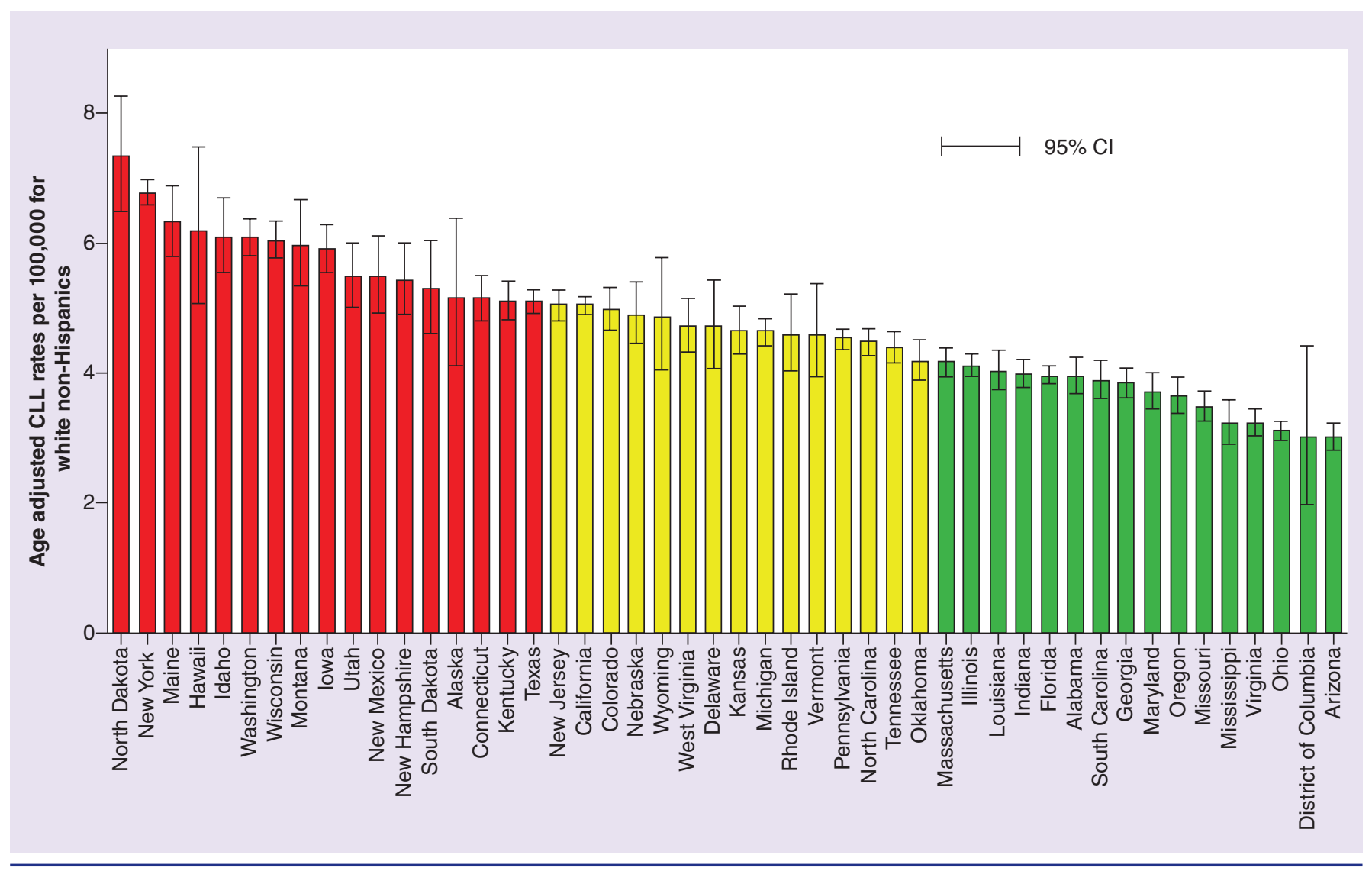

Figure 1. Age-adjusted incidence rates for chronic lymphocytic leukemia by US states 2007-2011 among white non-Hispanics. Bars are $95 \% \mathrm{Cl}$.

CLL: Chronic lymphocytic leukemia.

Data taken from [17].

The IWCLL 2008 revisions were associated with a $\sim 9 \%$ drop in CLL incidence rates nationwide, from a high of 4.70 cases per 100,000 for white non-Hispanics in 2007 to a low of 4.39 in 2011. The rank ordering of states was little affected. The correlation between statewide CLL rates for 2007-2008 and 2009-2011 was 0.820 (white males and females combined; $\mathrm{p}<0.001$ ). Similarly, the adjusted means of CLL rates were not significantly different between 2007 and 2011 and 2009 and 2011.

Statewide CLL rates for the time periods 2007-2011 and 2009-2011 were significantly positively correlated with the weighted measures of indoor radon levels (Table 1). This relationship was observed for blacks, whites (both genders together) and for white males and white females (each gender separately) for both time periods. There were no significant differences in the relationships between state radon levels and CLL rates for these four populations between 2007 and 2011 and 2009 and 2011 (all p > 0.05).
Thus, the association between CLL and radon was not dependent on the classification system for CLL. Figures 2 \& 3 show the scatter plots for CLL incidence rates and residential radon levels in white non-Hispanic males and females (respectively) for 2009-2011.

We used ANCOVA to test for significant difference in the adjusted means for blacks and whites and for differences in the slopes of the regression lines. The adjusted means of blacks (3.24) and whites (4.76) were significantly different $(\mathrm{p}<0.001)$. However, the slopes of the regression lines did not differ significantly $(p=0.60)$. We investigated several weighting schemes for radon levels (weights of 1,2 and $3 ; 1,3$ and $6 ; 1,3$ and 7, for low, moderate and high). The results from all weighting schemes were similar and all were statistically significant.

\section{Discussion}

Using population-based data on age-adjusted incidence rates of CLL in US states and measures 
Table 1. Relationship of average weighted state radon levels to chronic lymphocytic leukemia incidence rates by race and gender, 2007-2011 and 2009-2011.

\begin{tabular}{|llllll|} 
Population & $\begin{array}{l}\text { Number of } \\
\text { states }\end{array}$ & Slope & $95 \% \mathrm{Cl}$ & $\begin{array}{l}\text { Correlation } \\
\text { coefficient }\end{array}$ & p-value \\
\hline 2007-2011 & & & & & \\
White non-Hispanic & 48 & 0.299 & $(0.094-0.503)$ & 0.398 & 0.005 \\
Male & 48 & 0.415 & $(0.142-0.687)$ & 0.412 & 0.004 \\
\hline Female & 48 & 0.210 & $(0.061-0.359)$ & 0.386 & 0.007 \\
\hline Black non-Hispanic & 33 & 0.318 & $(0.072-0.564)$ & 0.428 & 0.013 \\
2009-2011 & & & & & \\
White non-Hispanic & 48 & 0.338 & $(0.128-0.549)$ & 0.430 & 0.002 \\
\hline Male & 47 & 0.382 & $(0.094-0.700)$ & 0.370 & 0.010 \\
\hline Female & 47 & 0.259 & $(0.106-0.411)$ & 0.453 & 0.001 \\
\hline Black non-Hispanic & 32 & 0.333 & $(0.006-0.660)$ & 0.355 & 0.046 \\
\hline
\end{tabular}

of radon measured in homes in each state, we observed significant positive correlations between incidence rates for CLL and residential radon levels. This relationship was significant separately for blacks and for whites, and individually for white males and white females. Significant relationships were observed for time periods that used the NCI-WG-96 and the IWCLL 2008 classifications.
The highest incidence rates for CLL were observed in North Dakota and New York (7.33 and 6.77 per 100,000, respectively). Numerous studies have reported increased risks for CLL among Jews of Ashkenazi (European) descent $[2,19-21]$. This may contribute to the high rate of CLL in New York, the US state with the largest Jewish population [22]. High rates for CLL were observed in several rural states, for

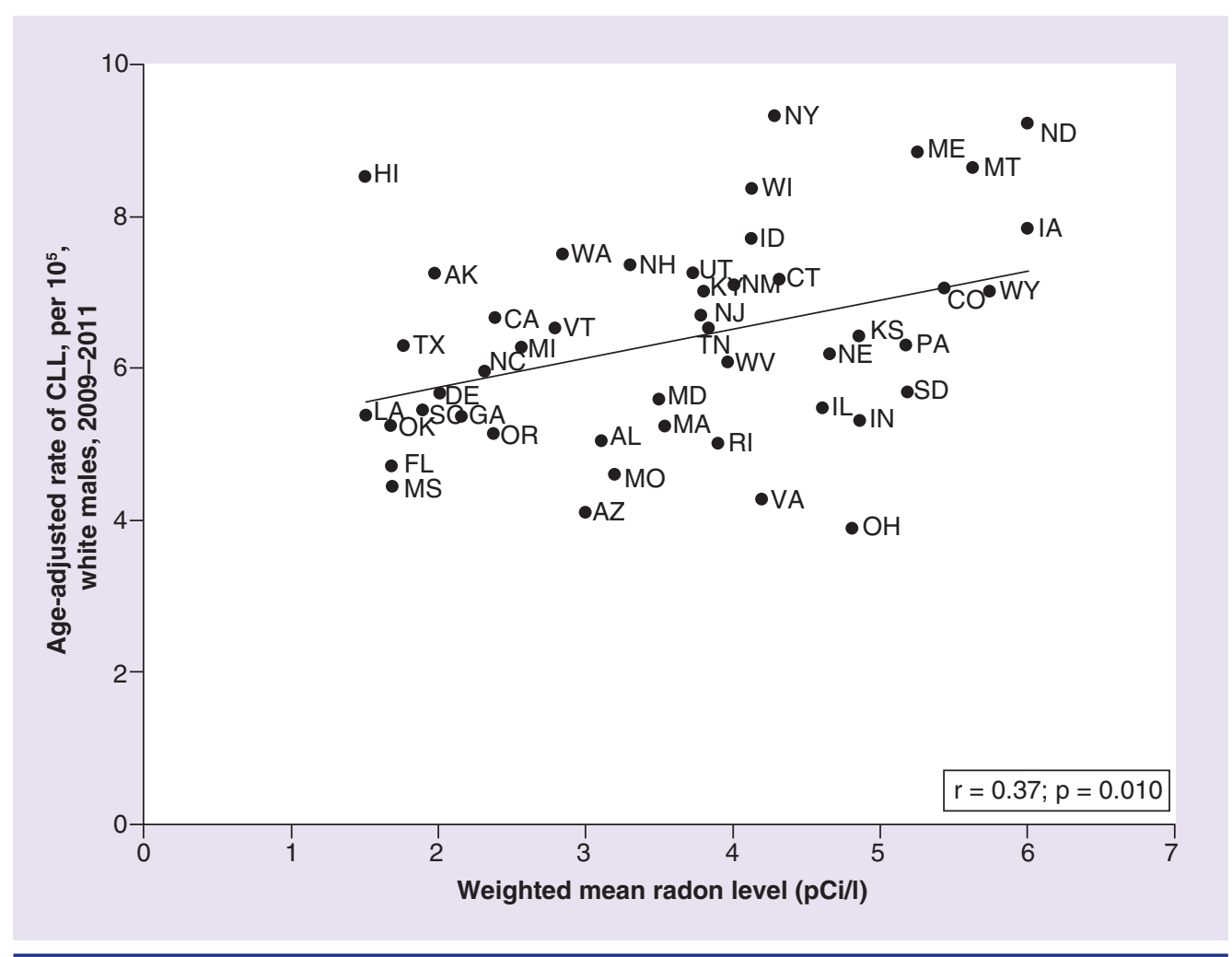

Figure 2. Scatter plot of age-adjusted incidence rates of chronic lymphocytic leukemia versus residential radon levels among males, white non-Hispanics, 2009-2011.

CLL: Chronic lymphocytic leukemia. 


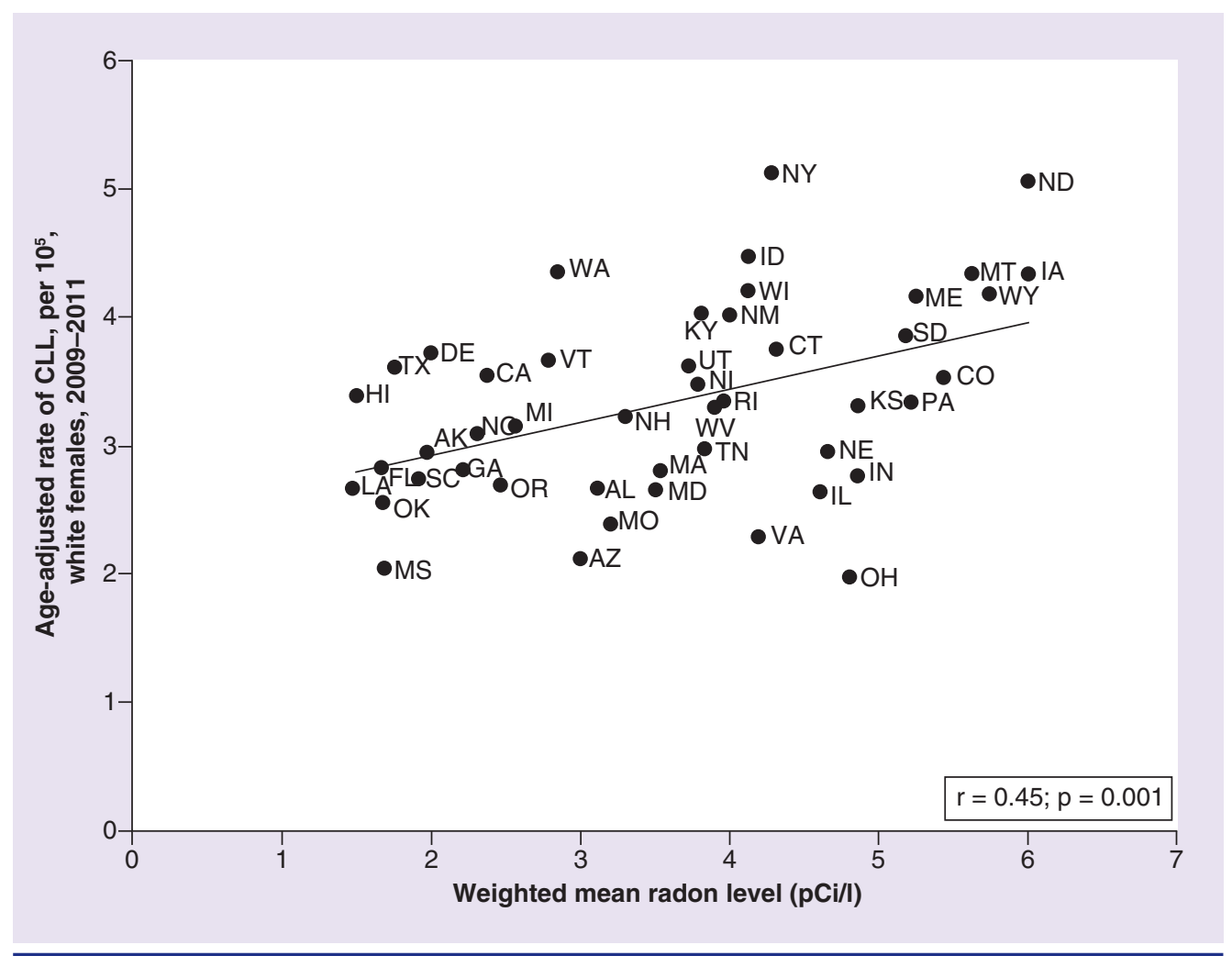

Figure 3. Scatter plot of age-adjusted incidence rates of chronic lymphocytic leukemia versus residential radon levels among females, white non-Hispanics, 2009-2011.

CLL: Chronic lymphocytic leukemia.

example, North Dakota, Montana and Maine. These rates are noteworthy since, with the advent of automated cell counting, most cases of CLL are diagnosed 'incidentally' during routine medical care [23]. Because residents of rural states typically utilize medical care less often than residents of non-rural states, the high rates of CLL in rural states are unlikely to reflect detection bias [24].

Our findings are consistent with findings from several smaller ecologic studies [25]. In 1990, Alexander and colleagues used data for 22 counties in England and Wales and reported a positive correlation between residential radon concentrations and several types of leukemia, including CLL [26]. Haque and Kirk performed a similar analysis using mortality data over a 37-year period [27]. However, because these studies were performed before the widespread use of flow cytometry, the diagnosis of CLL in these studies is less certain. A modern, methodologically sophisticated study using ecologic data within the state of Iowa reported (nonsignificant) positive associations between CLL and county-wide radon levels [28].
In contrast to ecologic studies, the results of analytic studies of individuals exposed to (mostly high levels) of ionizing radiation do not support an etiologic role for ionizing radiation in CLL [8,29]. As noted by Richardson and colleagues [9], an increased risk of CLL from exposure to ionizing radiation may be difficult to detect for several reasons, including the long asymptomatic period between exposure and disease and the low case fatality rate of CLL, which limits the usefulness of mortality data. Studies of individuals exposed to radiation for medical reasons have consistently shown modest increases in risk of CLL given a long follow-up (>15 years), although none have been statistically significant [30]. Conversely, reports of significantly elevated rates of CLL among uranium miners and among clean-up crew from the Chernobyl nuclear accident support a role for ionizing radiation [11,31], whereas data from other populations chronically exposed to low dose-rate radiation following environmental contamination do not [32]. Thus, the radiogenicity of CLL remains unresolved.

We found that the geographic distribution of incidence rates for CLL in the US is similar to 
the geographic distribution of residential radon levels. Our study has several limitations, including its ecological design and potential biases caused by migration, misclassification and confounding. CLL may have a latency of several decades [30]. Thus, individuals diagnosed in a given location may have migrated from the state where their etiologic exposure occurred. With the exception of North Dakota, which has experienced recent in-migration (predominantly of young men), the trend in migration has been for older residents of northern states to migrate southward, principally to Arizona and Florida (Figure 1) [33]. Thus, the effects of migration on the association between CLL and radon is likely to be conservative, as individuals with high exposure to radon in early life retire to states with low radon levels where they are diagnosed. Additionally, radon levels are heterogeneous within states and the use of an average radon level for the entire state may introduce misclassification. The effects of both types of misclassification should bias the association between radon exposure and CLL toward the null.

CLL has undergone several changes in classification. We observed similar associations between residential radon and CLL using cases defined pre- and post- the 2008 IWCLL 2008 revision. The WHO's 2001 classification of hematopoetic cancer classified small lymphocytic lymphoma (SLL) and CLL as different manifestations of the same disease (CLL/SLL) [34]. Although the inclusion of SLL cases with 'classical' CLL cases may vary among cancer registries [35], SLL cases comprise a small fraction of the total cases of CLL/SLL and variation in the registration of SLL is unlikely to introduce significant bias. Lastly, some misidentification of CLL with other B-cell lymphomas, for example, mantle cell lymphoma, is possible. However, many lymphomas that could be mistaken for CLL are rare and their misidentification is unlikely to materially influence incidence rates for CLL [36,37].

Our findings could reflect confounding by sunlight exposure. Many of the USA states with high levels of residential radon are located at northern latitudes, where levels of winter sunlight are low. Several studies [38-40] but not all [41], report a protective effect of exposure to sunlight on risk of CLL, for example, via time spent outdoors. Although a protective role of sunlight per se is possible, those data are also compatible with a radon model since individuals who spend more time outdoors, by definition, spend less time indoors, where radon levels are higher.
Most importantly, because this is an ecologic (group level) study it does not provide evidence that individuals with high radon exposures have an increased risk of CLL. Rather, it shows that incidence rates of CLL in US states increase significantly as radon levels in homes in these states increase. It is well known that ecologic studies, including those involving radon, can be misleading. For example, Cohen famously reported an inverse relationship between county wide radon levels and lung cancer, leading to the biologically implausible conclusion that small doses of radon protect against lung cancer $[42,43]$. Rejoinders by numerous scientists have shown that the effect reported by Cohen is due to confounding, where counties with high radon levels had low rates of smoking, the best known risk factor for lung cancer $[44,45]$. It is possible that our findings are due to confounding. However unlike lung cancer, there are no established environmental causes for CLL. If our results are due to confounding, we encourage speculation as to what the confounders could be, as their identification could uncover genuine risk factors for CLL.

Radon could cause CLL via several mechanisms. After inhalation, radon gas dissolves in the blood and circulates throughout the body. Radon could influence lymphocytes in the lungs, circulation and bone marrow. Because lymphocytes are abundant in the bronchial epithelium, radon could induce leukemia by mechanisms similar to its role in lung cancer, in other words: radon particles lodge in the respiratory epithelium and release $\alpha$ particles that damage lymphocyte DNA [46]. It is intriguing in this regard that rats exposed experimentally to radon develop lung tumors with frequent deletions at chromosome $15 \mathrm{q}$. This chromosomal region is homologous to human chromosome (HAS) bands 13q14.1-14.3/3p14.2 [47]. Deletion of chromosome $13 \mathrm{q} 14$ is found in the majority of cases of CLL at diagnosis and is considered to be an initiating lesion [48,49] Radon causes chromosomal damage to lymphocytes at low doses and dose ranges [50]. Relative to controls living in homes with low radon levels, a significant increase in chromosome aberrations was reported in the peripheral blood lymphocytes (PBLs) of individuals living in homes with elevated radon levels [51,52]. It is noteworthy that several large studies [53,54], but not all [55], have reported significant associations between residential radon and childhood leukemia.

Although a 'lung-cancer like' mechanism for radon in CLL is plausible, a radon hypothesis 
faces a conceptual difficulty: if chronic exposure to radon (i.e., ionizing radiation at low doses) increases risk, why do not most studies of individuals exposed to ionizing radiation at high doses show increased risk? One possibility is that the exposure to ionizing radiation from radon is via inhalation. Another possibility is the contrasting properties of initiation and inactivation [56]. In order for an exposure to be carcinogenic, affected cells must undergo genetic damage (initiation), yet survive. The initiated cells replicate to yield a population of damaged but replication-competent cells. Conversely, if the exposure is sufficiently high, affected cells die and cannot reproduce (inactivation). This produces the paradoxical result that that low exposure levels increase cancer risk but high levels do not. This possibility is supported by some studies of chromosome abnormalities. Oestricher and colleagues examined the prevalence of chromosome aberrations in PBLs in individuals living in homes with varying indoor radon concentrations. Compared to controls living in homes with radon levels $<200 \mathrm{~Bq} / \mathrm{m}^{3}$ (5.4 piC/l), the frequency of lymphocytes with dicentric and/or centric rings was significantly increased among individuals living in homes with radon levels of $200-1000 \mathrm{~Bq} / \mathrm{m}^{3}$ (5.4-27.0 pCi/l). However, there was no significant difference in the frequency of PBLs containing these aberrations between controls and individuals living in homes with much higher radon levels, 1000$13,000 \mathrm{~Bq} / \mathrm{m}^{3}$ (27.0-351 pCi/l) [48]. Similarly, Schubauer-Berigan and colleagues reported that CLL rates were increased among US nuclear facility workers at external doses between 10 and 100 mSv but not at exposures exceeding $100 \mathrm{mSv}$ [57]. These data support the hypothesis raised by these authors that "the association of CLL with ionizing radiation may be a predominantly low-dose phenomenon".

\section{Future perspective}

A CLL residential radon hypothesis makes numerous predictions that could be tested in analytic studies. For example, radon levels in homes of cases of CLL should be higher than in the homes of controls. Similarly, the homes of cases and controls may differ in structural characteristics that are associated with higher radon levels, such as the presence of a perimeter floor drain [58]. Radon concentrates in the lowest level of homes, and homes with basements

\section{EXECUTIVE SUMMARY}

- Chronic lymphocytic leukemia (CLL) is the most common leukemia in the western world, accounting for $30 \%$ of all leukemias.

- Its etiology is unknown and preventive strategies are unavailable.

- Most leukemias are caused by exposure to radiation; CLL has been considered to be an exception, since groups exposed to radiation at high doses do not show increased risks of CLL.

- The geography of CLL is not random; high rates occur in rural states in the northern and central USA, where access to specialized care is less common. High rates in these states are challenging to explain.

\section{Radon is a naturally occurring radioactive gas and for most individuals, it is the largest source of exposure to} ionizing radiation

- Age-adjusted incidence rates for CLL in US states are significantly correlated with high-quality measurements of radon in homes in these states.

- These findings are consistent for men, women, blacks and whites.

- The data suggest that exposure to ionizing radiation at low levels may cause CLL.

- The association between CLL and radon is at the level of the place and requires validation at the level of the individual.

- The presumed mechanisms whereby radon induces CLL are similar to the mechanisms whereby radon induces lung cancer.

\section{Future perspective}

- The association between CLL and residential radon suggests numerous hypotheses that could advance or refute the radon hypothesis.

- Many of these studies could be accomplished using a case-control design and obtaining residential histories of cases of CLL and controls. 
may have higher radon levels than homes without them [59]. Because radon levels are lower in higher floors of a dwelling, living in apartments (above the ground floor) should be protective. It would be informative to compare cases versus controls concerning time spent in basements, and, in particular, whether cases are more likely to have had their bedrooms in the basement.

\section{Conclusion}

In summary, we report that incidence rates for CLL in US states are significantly correlated with levels of residential radon. Similar significant correlations were found for whites, blacks and for white males and white females. Radon is known to damage lymphocyte DNA and its inhalation is a biologically plausible cause of CLL. A radon hypothesis for CLL suggests new avenues for epidemiologic research in a cancer whose investigation has been hampered by a paucity of promising clues.

\section{Acknowledgements}

The authors thank M Knovich for discussions on the MS.
Financial \& competing interests disclosure

The authors have no relevant affiliations or financial involvement with any organization or entity with a financial interest in or financial conflict with the subject matter or materials discussed in the manuscript. This includes employment, consultancies, honoraria, stock ownership or options, expert testimony, grants or patents received or pending, or royalties.

No writing assistance was utilized in the production of this manuscript.

\section{Ethical conduct of research}

The authors state that they have obtained appropriate institutional review board approval or have followed the principles outlined in the Declaration of Helsinki for all human or animal experimental investigations. In addition, for investigations involving human subjects, informed consent has been obtained from the participants involved.

\section{Open access}

This work is licensed under the AttributionNonCommercial-NoDerivatives 4.0 Unported License. To view a copy of this license, visit http://creativecommons.org/ licenses/by-nc-nd/4.0/

\section{References}

Papers of special note have been highlighted as: - of interest; $\bullet$ of considerable interest

1 Hallek M, Cheson BD, Catovsky D et al. Guidelines for the diagnosis and treatment of chronic lymphocytic leukemia: a report from the International Workshop on Chronic Lymphocytic Leukemia updating the National Cancer Institute-Working Group 1996 guidelines. Blood 111(5), 5446-5456 (2008).

2 Ruchlemer R, Polliack A. Geography ethnicity and "roots" in chronic lymphocytic leukemia. Leuk. Lymphoma 54(6), 1142-1150 (2013).

3 Nabhan C, Rosen ST, Chronic lymphocytic leukemia. A clinical review. JAMA 312(21), 2265-2276 (2014).

4 Wang SS, Slager SL, Brennan P et al. Family history of hematopoietic malignancies and risk of non-Hodgkin lymphoma (NHL): a polled analysis of 10,211 cases and 11,905 controls from the International Lymphoma Epidemiology Consortium (InterLymph). Blood 109(8), 3479-3488 (2007).

5 Tsai H-T, Cross AJ, Graubard BI, Oken M, Shatzkin A, Caporaso NE. Dietary factors and risk of chronic lymphocytic leukemia and small lymphocytic lymphoma: a pooled analysis of two prospective studies. Cancer Epidemiol. Biomarkers Prev. 19(10), 2680-2684 (2010).
6 Blair A, Purdue MP, Weisenburger DD, Baris D. Chemical exposures and risk of chronic lymphocytic leukaemia. Br. J. Haematol. 139(5), 753-761 (2007).

7 Slager SL, Benavente Y, Blair A et al. Medical history, lifestyle, family history, and occupational risk factors for chronic lymphocytic leukemia/small cell lymphocytic lymphoma: the Interlymph Non-Hodgkin Lymphoma Subtypes Project. J. Natl Cancer Inst. Monogr. 48, 241-251 (2014).

8 United Nations Scientific Committee on the Effects of Atomic Radiation (UNSCEAR). Epidemiologic evaluation of radiationinduced cancer. Annex I. In: Sources and Effects of Ionizing Radiation Volume 11. UNSCEAR, NY, USA, 298-450 (2000).

9 Richardson DB, Wing S, Schroeder J, Schmitz-Feurehake I, Hoffman W. Ionizing radiation and chronic lymphocytic leukemia. Environ. Health Perspect. 113(1), 1-5 (2005).

- An important paper that argues that epidemiologic studies may be insensitive to detect a true risk of ionizing radiation on chronic lymphocytic leukemia (CLL).

10 Hamblin TJ. Have we been wrong about ionizing radiation and chronic lymphocytic leukemia? Leuk. Res. 32(4), 523-525 (2011).

11 Rericha V, Kulich M, Rericha R, Shore DL, Sandler DP. Incidence of leukemia, lymphoma, and multiple myeloma in Czech uranium miners: a case-cohort study. Environ. Health Perspect. 114(4), 818-822 (2006).

12 Abramenko I, Bilous N, Chumak A et al. Chronic lymphocytic leukemia patients exposed to ionizing radiation due to the Chernobyl NPP accident - with focus on immunoglobulin heavy chain analysis. Leuk. Res. 32(4), 535-545 (2008).

13 Environmental Protection Agency. EPA Assessment of Risk from Radon in Homes. Office of Radiation and Indoor Air. US EPA, Washington, DC, USA. www.epa.gov/radon/risk_assessment.html

14 Committee on the Biological Effects of Ionizing Radiations. Health Effects of Exposure to Low Levels of Ionizing Radiation. Beir V. National Academy Press, Washington, DC, USA (1996). www.nap.edu/read/11340/chapter/1

15 Environmental Protection Agency. National Residential Radon Survey Summary Report. 02-R-92-011. nepis.epa.gov/Exe

16 Marcinowski F. Nationwide survey of residential radon levels in the US. Rad. Prot. Dosimetry 45(1), 419-424 (1991).

17 CINA+Online Cancer in North America. www.cancer-rates.info/naaccr/ 
18 Matasar MJ, Ritchie EK, Consedine CM, Neugut AI. Incidence rates of the major leukemia subtypes among U.S. Hispanics, Blacks, and non-Hispanic Whites. Leuk. Lymph. 47(11), 2365-2370 (2006).

19 Koller EK, MacMahon B. Ethnic differences in the incidence of leukemia. Blood 12(1), 1-10 (1957).

20 Shvidel L, Shtarlid M, Klepfish A, Sigler E, Berrebi A. Epidemiology and ethnic aspects of B cell chronic lymphocytic leukemia in Israel. Leukemia 12(10), 1612-1617 (1998).

21 Bartal A, Bentwich Z, Manny N, Izak G. Ethnical and clinical aspects of chronic lymphocytic leukemia in Israel: a survey on 288 patients. Acta Haematol. 60 (3), 161-171 (1978).

22 World Jewish population. www.simpletoremember.com

23 Oscier D, Fegan C, Hillmen P et al. Guidelines on the diagnosis and management of chronic lymphocytic leukaemia. $\mathrm{Br}$. J. Hematol. 125(3), 294-317 (2004)

24 Larson S, Correa-de-Araujo R. Preventive health examinations: a comparison along the rural-urban continuum. Womens Health Issues 16(2), 80-88 (2006).

25 Laurier D, Valenty M, Timarche M. Radon exposure and risk of leukemia: A review of epidemiologic studies. Health Phys. 81(3), 272-288 (2001).

26 Alexander FE, McKinney PA, Cartwright RA. Radon and leukaemia. Lancet 335, 1336-1337 (1990).

27 Haque A, Kirk A. Environmental radon and cancer risk. Radiat. Prot. Dosim. 45(1-4), 639-642 (1992).

28 Smith BJ, Zhang I, Field RW. Iowa leukemia radon study: a hierarchical population risk model for spatially correlated exposure measured with error. Stat. Med. 10(26), 4619-4642 (2007).

29 Little M, Weiss H, Boice J, Darby S, Day N, Muirhead C. Risks of leukemia in Japanese atomic bomb survivors, in women treated for cervical cancer, and in patients treated for ankylosing spondylitis. Radiat. Res. 152(3), 280-292 (1999).

30 Silver SR, Miratzka SL, Schubauer-Berigan MK, Daniels RD. Chronic lymphocytic leukemia radiogenicity: a systematic review. Cancer Causes Control 18(10), 1077-1093 (2007).

31 Kesminiene A, Evrard AS, Isanov VK et al. Risk of hematological malignancies among Chernobyl liquidators. Radiat. Res. 170(6), 721-735 (2008).
32 Kretinia LY, Davis FG, Schonfeld S, et al. Leukaemia incidence in the Techa River Cohort: 1953-2007. Br. J. Cancer 109(111), 2886-2893 (2013).

33 Aisch G, Gebeloff R, Quely K. Where we came from and where we went, state by state. www.nytimes.com/interactive

34 Jaffe ES, Harris NL, Stein H, Vardiman JW. World Health Organization Classification of Tumours: Pathology and Genetics of Tumours of Haematopoietic and Lymphoid Tissues. IARC Press, Lyon, France (2001).

35 Dores GM, Anderson WF, Curtis RE et al. Chronic lymphocytic leukaemia and small lymphocytic lymphoma: overview of the descriptive epidemiology. Br. J. Haematol. 139(5), 808-819 (2007).

36 Morton LM, Wang SS, Devesa SS, Hartge P, Weisenberger DD, Linet MS. Lymphoma incidence patterns by WHO subtype in the United States, 1992-2001. Blood 107(1), 265-276 (2006).

37 Matutes E, Wotherspoon A, Catovsky D. Differential diagnosis in chronic lymphocytic leukemia. Best Pract. Res. Clin. Haematol. 20(3), 367-384 (2007).

38 Luczynska A, Kaaks R, Rohrmann S et al. Plasma 25-hydroxyvitamin D concentration and lymphoma risk: results of the European Prospective Investigation into Cancer and Nutrition. Am. J. Clin. Nutr. 98(3), 827-838 (2013).

39 Smedby KE, Kjalgrim H, Melbye $\mathrm{M}$ et al. Ultraviolet radiation exposure and risk of malignant lymphomas. J. Natl Cancer Inst. 97(3), 199-209 (2005).

40 Chang ET, Canchola AJ, Cockburn M et al. Adult residential ultraviolet radiation, sun sensitivity, dietary vitamin $\mathrm{D}$, and risk of lymphoid malignancies in the California Teachers Study. Blood 118(6), 1592-1599 (2011).

41 Adami J, Gridley G, Nyrén O et al. Sunlight and non-Hodgkin's lymphoma: a populationbased cohort study in Sweden. Int. J. Cancer 80(5), 641-645 (1999).

42 Cohen BL. A test of the linear no-threshold theory of radiation carcinogenesis. Environ. Res. 53(2), 193-220 (1990).

43 Cohen BL. Test of the linear no-threshold theory of radiation carcinogenesis for inhaled radon decay products. Health Phys. 68(2), 157-174 (1995).

44 Lubin JH. On the discrepancy between epidemiologic studies in individuals of lung cancer and residential radon and Cohen's ecologic regression. Health Phys. 75 (2), 4-10 (1998).
45 Puskin JS. Smoking as a confounder in ecologic correlations of cancer mortality rates with average county radon levels. Health Phys. 84(4), 526-532 (2003).

46 Harley NH, Robbins ES. Radon and leukemia in the Danish Study: another source of dose. Health Phys. 97(4), 343-347 (2009).

-. The authors describe a possible mechanism whereby radon could induce leukemia via interaction with lymphocytes in the bronchial epithelium.

47 Dano L, Guilly MN, Muleus M et al. CGH analysis of radon-induced rat lung tumors indicates similarities with human lung cancers. Genes Chromosomes Cancer 29(1) $1-8(2000)$.

-. The authors describe a model of radoninduced rat lung tumors. Frequent losses of genetic material occurred at $15 \mathrm{q}$, an area that is homologous with human chromosome 13q14, which is the most common mutation at diagnosis of CLL.

48 Gaidani G, Foá R, Dalla-Favera R. Molecular pathogenesis of chronic lymphocytic leukemia. J. Clin. Invest. 122(10), 3422-3438 (2012).

49 Calin GA, Dumitru CD, Shimizu M et al. Frequent deletions and down-regulation of micro-RNA genes miR15 and miR16 at 13q14 in chronic lymphocytic leukemia. Proc. Natl Acad. Sci. USA 99 (24), 15524-15529 (2012).

50 Zareena Hamza V, Mohankumanr MN. Cytogenetic damage in human blood lymphocytes exposed in vitro to radon. Mutat. Res. 661(1-2), 1-9 (2008).

51 Bauchinger M, Schmid E, Braselmann H, Kalka U. Chromosome aberrations in peripheral lymphocytes from occupants of houses with elevated indoor radon concentrations. Mutat. Res. 310(1), 135-142 (1994).

52 Oestreicher U, Braselmann H, Stephan G. Cytogenetic analyses in peripheral lymphocytes of persons living in houses with increased levels of indoor radon concentrations. Cytogenet. Genome Res. 104(1-4), 232-236 (2004).

53 Kendall GM, Little MP, Wakeford R et al. A record-based case-control study of natural background radiation and the incidence of childhood leukaemia and other cancers in Great Britain during 1980-2006. Leukemia 27(1), 3-9 (2013).

54 Raaschou-Nielsen O, Andersen CE, Andersen HP et al. Domestic radon and childhood cancer in Denmark. Epidemiology 19(4), 536-543 (2008). 
55 Lubin JH, Linet MS, Boice Jr JD et al. Case-control study of acute lymphoblastic leukemia and residential radon exposure. J. Natl Cancer Inst. 90 (4), 294-300 (1998).

56 Gray LH. Radiation biology and cancer. In: Cellular Radiation Biology: a Symposium Considering Radiation Effects in the Cell and Possible Implications for Cancer Therapy. Williams and Wilkins Co., Baltimore, MD, USA, 8-25 (1965).

57 Schubauer-Berigan MK, Daniels RD, Fleming DA et al. Chronic lymphocytic leukaemia and radiation: findings among workers at five US nuclear facilities and a review of the recent literature. $B r . J$. Haematol. 139(5), 799-808 (2007).

- The authors' discussion raises the provocative hypothesis that "the association of CLL with ionizing radiation may be a predominantly low-dose phenomenon".

58 Shendell DG, Carr M. Physical conditions of a house and their effects of measured radon levels: data from Hillsborough Township,
New Jersey, 2010-2011. J. Environ. Health 76(3), 18-25 (2013).

- The data from this descriptive study illustrate how housing characteristics could be used as exposure variables in analytic epidemiologic studies.

59 Borgoni R, De Francesco D, De Bartolo D, Tzavidid N. Hierarchical modeling of indoor radon concentration: how much do geology and building factors matter? J. Environ. Radioactivity 138(12), 297-237 (2014) 